\title{
Evaluation of the Effect of Continuous Infusion of Dexmedetomidine or a Subanesthetic Dose Ketamine on Transcranial Electrical Motor Evoked Potentials in Adult Patients Undergoing Elective Spine Surgery under Total Intravenous Anesthesia: A Randomized Controlled Exploratory Study
}

\author{
Roshan Andleeb, Sanjay Agrawal, Priyanka Gupta \\ Department of Anaesthesiology and Critical Care, All India Institute of Medical Sciences, Rishikesh, India
}

\section{Study Design: Prospective, randomized, placebo-controlled, double-blind exploratory study.}

Purpose: To compare effects of dexmedetomidine or a subanesthetic dose of ketamine on the amplitude and latency of transcranial electrically generated motor evoked potentials.

Overview of Literature: Total intravenous anesthesia (TIVA) is a standard anesthesia technique for transcranial electrical motor evoked potential monitoring in spine surgery. We aimed to determine whether the use of dexmedetomidine and ketamine as a component of TIVA exerted any beneficial effect on the quality of monitoring.

Methods: A total of 90 American Society of Anesthesiologist grade I-III patients, aged 18-65 years, with a motor power of $\geq 4 / 5$ grade as per the Medical Research Council Scale in all four limbs who were scheduled for elective spine surgery under transcranial electrical motor evoked potential monitoring were enrolled. The subjects were randomly allocated into the following three groups: group PD who received $0.5 \mu \mathrm{g} / \mathrm{kg} / \mathrm{hr}$ dexmedetomidine infusion, group PK who received $0.5 \mathrm{mg} / \mathrm{kg} / \mathrm{hr}$ ketamine infusion, and group PS who received normal saline infusion, along with standard propofol-fentanyl based TIVA regime. Amplitude and latency of bilateral motor evoked potentials of the tibialis anterior and abductor halluces muscle were recorded at Ti (at train-of-four ratio >90\%), T30 (30 minutes post-Ti), T60 (60 minutes post-Ti), and Tf (at the end of spine manipulation).

Results: Baseline median amplitudes were comparable among the study groups. In group PK, we noted a gradually enhanced response by $24 \%-100 \%$ from the baseline amplitude. The median amplitudes of all the muscles were higher in group PK than those in groups PS and PD at time points T60 and Tf $(p<0.05)$.

Conclusions: The present study demonstrated that compared with dexmedetomidine and control treatment, a subanesthetic dose of ketamine caused gradual improvement in amplitudes without affecting the latency.

Keywords: Spine surgery; Motor evoked potentials; Ketamine; Dexmedetomidine

Received Feb 19, 2021; Revised Feb 19, 2021; Accepted Feb 24, 2021

Corresponding author: Sanjay Agrawal

Department of Anaesthesiology \& Critical Care, All India Institute of Medical Sciences, Rishikesh, Uttarakhand 249203, India

Tel: +91-1352460994, Fax: +91-1352462941, E-mail: sanjay.anaes@aiimsrishikesh.edu.in 


\section{Introduction}

Transcranial electrical motor evoked potential (TceMEP) monitoring has gained prominence as an integral modality of monitoring in the field of spine surgery. It monitors the functional integrity of the motor cortex, corticospinal tract, $\alpha$-motor neuron, peripheral nerve, and neuromuscular junction. TceMEP monitoring has high sensitivity and specificity in the detection of postoperative newonset motor deficits and is currently considered the gold standard with $91 \%$ sensitivity and $96 \%$ specificity [1]. Several physiological factors, such as hyperthermia, hypothermia, hypotension, hypocapnia, hypercapnia, blood loss, hypoxemia, hypoglycemia, hyperglycemia, electrolyte imbalance, and intracranial hypertension, influence perioperative neuromonitoring [2]. Certain anesthetic agents influence motor evoked potentials (MEP) via their effects on direct suppression of the excitability of cortical and spinal motor neurons, interference with synapse transmission, or alteration in the balance of inhibitory or excitatory influences on the synaptic pathway [2]. Neuromuscular agents, inhalational anesthetic agents, and nitrous oxide are potent suppressants of MEP [2].

The American Society of Neurophysiological Monitoring recommends propofol-opioid based total intravenous anesthesia (TIVA) as the ideal regime for MEP monitoring [3]. Opioid has minimal influence; however, propofol demonstrates a dose-dependent reduction in amplitudes without affecting the latency $[2,4]$. Prolonged usage of propofol is associated with prolonged awakening, lipemia, platelet dysfunction, metabolic acidosis, and propofol infusion syndrome [2,5]. Anesthesia fade or fading MEPs is a phenomenon observed in MEP response under TIVA, and anecdotal reports suggest that the total dose of propofol is a contributing factor [6].

The modified Delphi consensus recommendations advocate the use of TIVA with adjuvant (ketamine, dexmedetomidine, and lidocaine) along with standard TIVA regime without affecting MEP signals [7].

Ketamine is used as either an infusion or intermittent boluses in nitrous oxide or opioid-based anesthetic regimens with or without neuromuscular blockade [814]. Studies have demonstrated the potentiation of MEPs; however, the occurrence of psychotomimetic adverse effects, hypertension, and delayed extubation have discouraged its use [9,10,12-14].

Dexmedetomidine, an $a 2$ agonist that possesses anal- gesic, sedative, and sympatholytic properties, has recently been explored as an adjunct to TIVA for MEP monitoring in spine surgery. This agent has demonstrated compatibility with intraoperative MEP monitoring along with the lower intraoperative requirement of opioids and propofol [15].

Hence, the present study was designed to evaluate and compare the effects of fixed doses of dexmedetomidine or ketamine as adjuvant therapy to propofol-fentanyl based TIVA in adult patients undergoing elective spine surgery under neuromonitoring.

\section{Materials and Methods}

\section{Study design}

The study was conducted after obtaining approval from the Institutional Ethics Committee of All India Institute of Medical Sciences, Rishikesh, India (ECR/736/Inst/ UK/2015/RR-18) and getting written informed consent from 90 patients of either sex with a motor power of $\geq 4 / 5$ grade as per the Medical Research Council Scale in all four limbs and American Society of Anesthesiologist physical status I-III scheduled for elective spine surgery under TceMEP between August 2019 and 2020. Patients with significant cardiovascular (uncontrolled hypertension, heart block, and heart failure), pulmonary, renal, hepatic, psychiatric, or neuromuscular disease; those with a history of chronic alcohol use or allergy to study drugs; those with hemoglobin $\leq 10 \mathrm{~g} / \mathrm{dL}$; those with body mass index $>30 \mathrm{~kg} / \mathrm{m}^{2}$; and those with contraindications to MEP monitoring (epilepsy, cortical lesion, raised intracranial tension, pacemaker, intracranial electrodes, or vascular clips), and acute spinal cord injury were excluded from the study. The trial was registered with the Clinical Trials Registry India (CTRI/2019/08/020645).

\section{Randomization and blinding}

Patients were randomly allocated to the groups to receive $0.5 \mu \mathrm{g} / \mathrm{kg} / \mathrm{hr}$ dexmedetomidine (group PD), $0.5 \mathrm{mg} / \mathrm{kg} / \mathrm{hr}$ ketamine (group PK), and normal saline (group PS). Computer-generated table of random numbers was used for the random allocation of the subjects in the study groups. The random numbers were placed in opaque and sealed envelopes. An anesthesiologist who was not involved in the study prepared the study drug, as per group allocation, in $50 \mathrm{~mL}$ syringes as infusate with normal saline (concentra- 
tion of dexmedetomidine and ketamine was $4 \mu \mathrm{g} / \mathrm{mL}$ and $4 \mathrm{mg} / \mathrm{mL}$, respectively). Patients, anesthesiologists, neurophysiologists, and surgeons were blinded to the group allocation of patients throughout the study.

All the eligible patients were kept nil per oral for solid food for 6 hours and clear fluids for 2 hours. Sedative premedication was omitted. After shifting to the operating room and initiating intravenous access, pulse oximeter, electrocardiography, noninvasive blood pressure, and noninvasive Bispectral index (BIS) monitors were attached. Anesthesia induction in all the patients was achieved with injection of $2 \mu \mathrm{g} / \mathrm{kg}$ fentanyl, $2.5 \mathrm{mg} / \mathrm{kg}$ propofol, and $1.2 \mathrm{mg} / \mathrm{kg}$ rocuronium to facilitate tracheal intubation with an appropriately sized endotracheal tube. Anesthesia was maintained with infusions of propofol $(50-150 \mu \mathrm{g} / \mathrm{kg} / \mathrm{hr})$ and fentanyl $(0.5-2 \mu \mathrm{g} / \mathrm{kg} / \mathrm{hr})$ with $50 \%$ oxygen in air. Study drugs as per group allotment were started after securing the airway. Ventilation was adjusted to maintain end-tidal carbon dioxide between 35 $\mathrm{mm} \mathrm{Hg}$ and $45 \mathrm{~mm} \mathrm{Hg}$ and the BIS between 40 and 60 . The temperature was monitored using a nasopharyngeal temperature probe and maintained at $>34^{\circ}$. The left radial artery was cannulated for invasive blood pressure monitoring, and the neuromuscular blockade was monitored using a train-of-four (TOF) recovery ratio (assessed using a TOF stimulation of the ulnar nerve at the left wrist). A dedicated neurophysiologist who used the NIM-Eclipse (Medtronic, Minneapolis, MN, USA) neurophysiologic monitoring system conducted TceMEP monitoring. Paired subdermal needle electrodes were used bilaterally in the tibialis anterior and abductor halluces muscles. The stimulating corkscrew electrodes were placed at the C3 and C4 sites (international 10-20 system). A train of six pulses ( $0.5 \mathrm{~ms}$ pulse duration, $2 \mathrm{~ms}$ interstimulus interval) at $250-500$ volts was utilized for electrical stimulus. Baseline pulses and voltage were established and maintained throughout the surgery.

Surgeries were performed with the patient in the prone position with protection of eyes and pressure points. Muscle paralysis was allowed to wear off, as evident by the TOF ratio. The baseline MEP $\left(\mathrm{T}_{\mathrm{i}}\right)$ was recorded on achieving TOF ratio of $>90 \%$, and subsequent recordings were noted at 30 and 60 minutes after $\mathrm{Ti}\left(\mathrm{T}_{30}\right.$ and $\left.\mathrm{T}_{60}\right)$; the final recording was made immediately after the surgical procedure was completed $\left(\mathrm{T}_{\mathrm{f}}\right)$.

Fentanyl and study drug infusions were stopped at the commencement of skin closure, whereas propofol infu- sion was stopped at the end of skin closure. The trachea was extubated after placing the patient in the supine position, with the BIS between 80 and 100. The immediate recovery (duration from discontinuation of propofol infusion to eye opening on verbal command) and extubation time (discontinuation of propofol and extubation) were recorded. The patients were transferred to the postanesthesia care unit (PACU) and were discharged when they achieved a Modified Aldrete Score of $\geq 9$. Pain was assessed using a Numerical Rating Scale (NRS) on arrival to the PACU, on discharge from the PACU, and 24 hours postoperatively. Postoperative pain was managed with intravenous injections of tramadol $2 \mathrm{mg} / \mathrm{kg}$ and paracetamol $15 \mathrm{mg} / \mathrm{kg}$ that were administered every 8 hours. If the NRS score was $>6$, an intravenous injection of $75 \mathrm{mg}$ diclofenac was administered.

\section{Statistical analyses}

There is a paucity of related literature; hence, no prior formal power calculation was undertaken. For sample size calculation we used the "Pilot Study Sample Size Rules of Thumb" procedure of PASS ver. 16.0 sample size software (NCSS, Kaysville, UT, USA); the calculated sample size was 83.5 [16]. We included 90 patients, with 30 subjects in each study group.

Statistical analyses were performed using IBM SPSS ver. 26.0 (IBM Corp., Armonk, NY, USA). Categorical variables are presented as frequencies or proportions and were analyzed using the chi-square test or Fisher's exact test. Quantitative data were analyzed for normal distribution using the Shapiro-Wilk test. Normally distributed data are presented as mean \pm standard deviation values, and data with non-normal distribution are presented as median with 25 th and 75 th percentile values (interquartile range). For normally distributed data, the means were compared using one-way analysis of variance after testing for the homogeneity of variance; post hoc analysis was conducted using Tukey's test for variables with significant $p$-values. For skewed data, independent sample Kruskal-Wallis $\mathrm{H}$ test was used for intergroup analysis, and significant results were further analyzed using Dunn's multiple pairwise comparison test. Related-Samples Friedman two-way analysis of variance by ranks was used for the intragroup analysis, and post hoc analysis with Wilcoxon signed-rank test was conducted. All the statistical tests were two-sided and were performed at a significance level of $p<0.05$. 


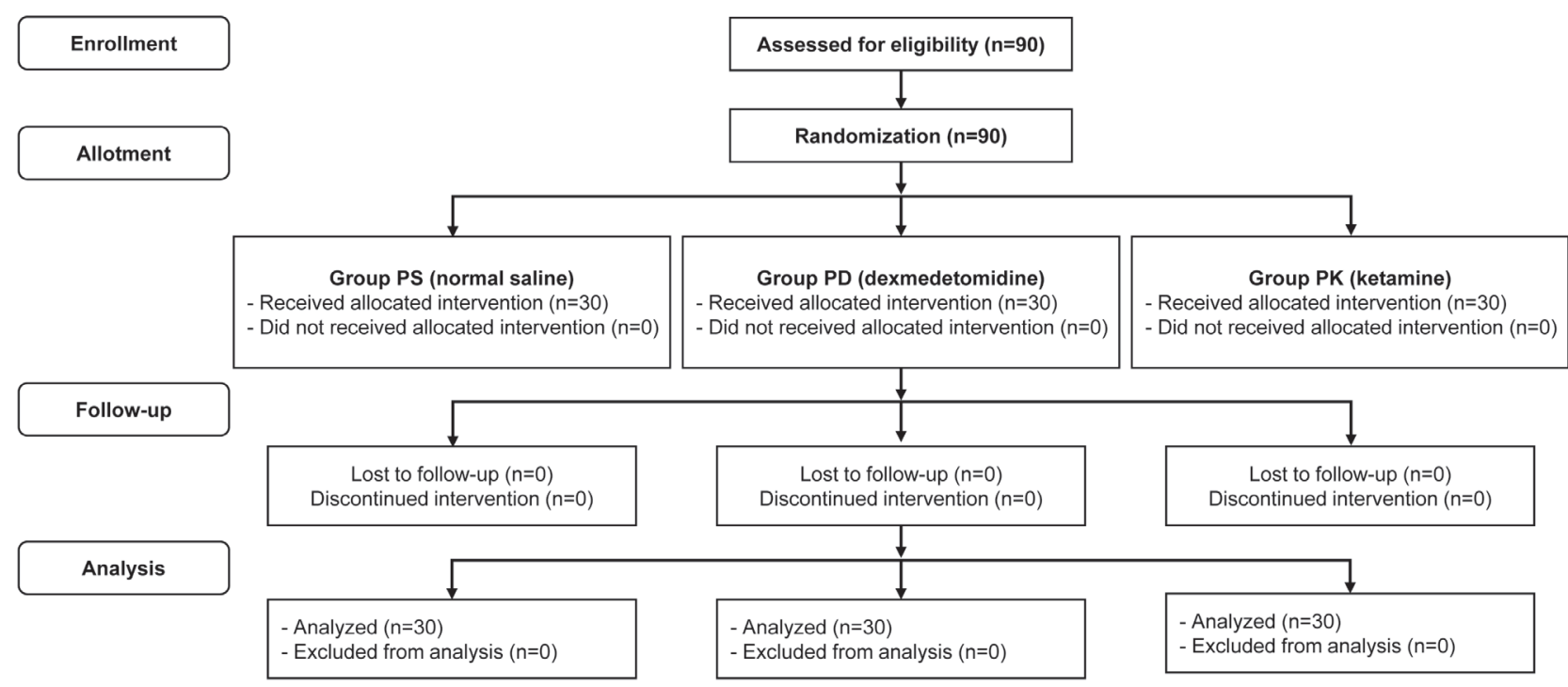

Fig. 1. CONSORT (Consolidated Standards of Reporting Trials) flow diagram. Group PS, patients to receive normal saline; group PD, patients to receive $0.5 \mu \mathrm{g} / \mathrm{kg} / \mathrm{hr}$ dexmedetomidine; group PK, patients to receive $0.5 \mathrm{mg} / \mathrm{kg} / \mathrm{hr}$ ketamine.

\section{Results}

Patient flow and randomization assignment are presented in the CONSORT (Consolidated Standards of Reporting Trials) flow diagram (Fig. 1). Ninety patients were enrolled and analyzed in the study. The demographic profile and preoperative variables of the subjects in all the groups were comparable (Table 1).

\section{Primary outcomes}

The average time to achieve TOF $>90 \%$ after the administration of rocuronium was comparable $(p=0.129)$ (Table $1)$. The baseline median amplitude and mean latency were comparable among the groups $(p>0.05)$. Intragroup analysis demonstrated higher median amplitude in group PK than those in groups PS and PD at time points T60 and Tf $(p>0.05)$ (Table 2). The amplitude increased $24 \%-100 \%$ in group PK, $0.5 \%-101 \%$ in group PD, and $-12 \%$ to $+0.9 \%$ in group PS (Table 3 ). The average latencies of the recorded MEPs at different time points were comparable in the study groups (Table 4).

\section{Secondary outcomes}

Changes in intraoperative hemodynamic parameters (heart rate and mean arterial pressure [MAP]) are shown in Fig. 2. Group PD had lower heart rate and MAP after
60 minutes and 75 minutes of starting drug infusion respectively, in comparison with groups PK and PS. The BIS value became significantly higher within 30 minutes of starting the drug infusion in group PK (Fig. 2). Table 5 presents the data on total propofol and fentanyl usage, postoperative pain score, rescue analgesic requirement, and complications. Propofol use was significantly lower in group PD than that in group PS ( $p=0.039$ ); the use was comparable in groups PS and PK $(p=0.674)$. Response to verbal command and extubation were faster in group PD $(p<0.05)$. A high incidence of delirium or disorientation was observed in group PK (6/30). The NRS score of group PD was lower, both after arrival to and departure from the PACU; however, at 24 hours, it was comparable in all the groups. A higher incidence of rescue analgesic usage was observed in groups PK and PS (27/30 and 23/30, respectively), whereas only 16 of the 30 patients in group PD required additional analgesics.

\section{Discussion}

Our study demonstrated progressive and sustained improvement in the amplitudes without any change in the latency of MEPs with subanesthetic ketamine $(0.5 \mathrm{mg} / \mathrm{kg} /$ hr) infusion in comparison with that with dexmedetomidine infusion.

Subanesthetic dose of ketamine acts on the non$\mathrm{N}$-methyl-D-aspartate (NMDA) receptors (AMPA 
Table 1. Demographic profile and perioperative profile of patients

\begin{tabular}{|c|c|c|c|c|}
\hline Characteristic & Group PS $(n=30)$ & Group PD ( $n=30)$ & Group PK $(n=30)$ & $p$-value \\
\hline Age (yr) & $39.83 \pm 14.14$ & $42.73 \pm 14.86$ & $43.77 \pm 14.56$ & 0.557 \\
\hline Sex (female/male) & $16 / 14$ & $09 / 21$ & $15 / 15$ & 0.244 \\
\hline Weight (kg) & $57.97 \pm 12.74$ & $61.13 \pm 14.26$ & $57.37 \pm 11.41$ & 0.478 \\
\hline American Society of Anesthesiologist status (I/II) & $26 / 4$ & $23 / 7$ & $22 / 8$ & 0.186 \\
\hline Diagnosis & & & & 0.918 \\
\hline Traumatic fracture & 13 & 15 & 13 & \\
\hline Pott's spine & 8 & 5 & 5 & \\
\hline Prolapsed intervertebral disc & 3 & 2 & 3 & \\
\hline Canal stenosis & 2 & 3 & 3 & \\
\hline Spinal tumor & 2 & 4 & 3 & \\
\hline Scoliosis/kyphosis & 1 & 1 & 3 & \\
\hline Atlanto-axial dysplasia & 1 & 0 & 0 & \\
\hline Surgery & & & & 0.072 \\
\hline Anterior cervical corpectomy and fusion & 1 & 1 & 0 & \\
\hline Anterior cervical discectomy and fusion & 6 & 4 & 1 & \\
\hline Posterior C1C2 fixation & 0 & 1 & 2 & \\
\hline Deformity correction & 1 & 1 & 3 & \\
\hline Laminectomy and tumor excision & 2 & 3 & 3 & \\
\hline Minimal invasive surgery & 1 & 1 & 2 & \\
\hline Odontoid surgery and foramen magnum decompression & 1 & 0 & 0 & \\
\hline Posterior decompression and instrumentation & 10 & 13 & 11 & \\
\hline Transforaminal lumbar interbody fixation & 8 & 6 & 8 & \\
\hline Duration of anesthesia (min) & $310.17 \pm 77.99$ & $314.14 \pm 111.54$ & $329.83 \pm 95.94$ & 0.705 \\
\hline Duration of surgery (min) & $230.83 \pm 78.84$ & $245.17 \pm 108.82$ & $256.83 \pm 91.89$ & 0.564 \\
\hline Baseline heart rate (/min) & $89.40 \pm 15.87$ & $89.07 \pm 10.68$ & $89.97 \pm 17.58$ & 0.973 \\
\hline Baseline mean arterial pressure $(\mathrm{mm} \mathrm{Hg})$ & $101.50 \pm 7.59$ & $100.23 \pm 9.09$ & $96.87 \pm 8.31$ & 0.091 \\
\hline Time to achieve train of four $>90 \%$ (min) & $45.87 \pm 6.40$ & $49.30 \pm 7.0$ & $48.30 \pm 6.61$ & 0.129 \\
\hline
\end{tabular}

Values are presented as mean \pm standard deviation or number.

Group PS, patients to receive normal saline; group PD, patients to receive $0.5 \mu \mathrm{g} / \mathrm{kg} / \mathrm{hr}$ dexmedetomidine; group PK, patients to receive $0.5 \mathrm{mg} / \mathrm{kg} / \mathrm{hr} \mathrm{ketamine}$.

[a-amino-3-hydroxy-5-methyl-4-isoxazolepropionic acid] and kainate receptor) and releases endogenous excitatory amino acids, glutamate, and aspartate, resulting in excitability of the motor cortex [17]. High-frequency stimulation during TcMEP causes further activation of these nonNMDA receptors, facilitating the MEP response in the presence of ketamine [17].

Our results are in agreement with those of various other authors. Kalkman et al. [8] and Kothbauer et al. [9] reported $150 \%-220 \%$ and $14 \%-137 \%$ increases in the amplitudes, respectively, with the use of only ketamine as the anesthetic agent. Inoue et al. [10] observed significantly larger amplitudes with $1 \mathrm{mg} / \mathrm{kg} / \mathrm{hr}$ ketamine than with control; however, augmentation with subanesthetic ketamine boluses has been demonstrated by Ubags et al. [11] and Benuska et al. [12]. Diminished MEP depression with propofol infusion in combination with ketamine has been demonstrated by Sihle-Wissel et al. [13]. We demonstrated an increase of $24 \%-100 \%$ in the amplitude with 0.5 $\mathrm{mg} / \mathrm{kg} / \mathrm{hr}$ ketamine infusion.

Few studies have reported on the use of dexmedetomidine as a component of TIVA and its effect on MEP. Tobias et al. [18] reported a nonsignificant improvement in amplitudes measured before and after a loading dose of dexmedetomidine ( $1 \mu \mathrm{g} / \mathrm{kg}$ over 20 minutes). Bala et al. [19] could not demonstrate any significant effect on 
Table 2. Intergroup analysis of amplitudes of motor evoked potentials at different time intervals in the study groups

\begin{tabular}{|c|c|c|c|c|c|c|}
\hline Amplitude $(\mu \mathrm{V})$ & Time (min) & Group PS (n=30) & Group PD $(n=30)$ & Group PK (n=30) & $p$-value & Post hoc analysis ( $p$-value) \\
\hline \multirow[t]{4}{*}{ Right tibialis anterior } & $\mathrm{T}_{\mathrm{i}}$ & $563(313-940)$ & $408(190-660)$ & 587 (289-847) & 0.183 & \\
\hline & $\mathrm{T}_{30}$ & $578(340-1,043)$ & 567 (225-730) & 742 (455-945) & 0.181 & \\
\hline & $\mathrm{T}_{60}$ & 569 (290-988) & $587(235-961)$ & $948(475-1,406)$ & $0.048^{*}$ & PS vs. PK (0.047) \\
\hline & $T_{f}$ & $497(248-854)$ & 506 (313-901) & $950(593-1,630)$ & $0.019^{*}$ & PS vs. PK (0.032) \\
\hline \multirow[t]{4}{*}{ Left tibialis anterior } & $\mathrm{T}_{\mathrm{i}}$ & $665(389-1,020)$ & 409 (250-694) & 527 (289-988) & 0.204 & \\
\hline & $\mathrm{T}_{30}$ & $664(409-1,077)$ & $684(285-1,058)$ & $715(429-1,593)$ & 0.653 & \\
\hline & $\mathrm{T}_{60}$ & $590(398-1,130)$ & $747(426-1,183)$ & $757(579-1,664)$ & 0.163 & \\
\hline & $T_{f}$ & $588(396-950)$ & $824(452-1,295)$ & $1,003(558-1,717)$ & $0.048^{*}$ & PS vs. PK (0.042) \\
\hline \multirow[t]{4}{*}{ Right abductor halluces } & $\mathrm{T}_{\mathrm{i}}$ & $811(451-1,083)$ & $511(309-1,226)$ & $782(439-1,009)$ & 0.654 & \\
\hline & $\mathrm{T}_{30}$ & $809(441-1,005)$ & $570(337-1,231)$ & $973(554-1,211)$ & 0.512 & \\
\hline & $\mathrm{T}_{60}$ & $706(418-1,113)$ & $638(326-1,333)$ & $1,197(677-1,783)$ & $0.025^{*}$ & PS vs. PK (0.046) \\
\hline & $T_{f}$ & 818 (420-996) & $604(283-1,920)$ & $1,401(579-1,996)$ & $0.033^{*}$ & PS vs. PK (0.049) \\
\hline \multirow[t]{4}{*}{ Left abductor halluces } & $\mathrm{T}_{\mathrm{i}}$ & 762 (486-990) & $556(287-1,319)$ & 713 (347-989) & 0.751 & \\
\hline & $\mathrm{T}_{30}$ & 749 (498-891) & $559(277-1,110)$ & $987(622-1,249)$ & 0.122 & \\
\hline & $\mathrm{T}_{60}$ & $678(458-944)$ & $565(217-1,459)$ & $1,140(599-1,732)$ & $0.023^{*}$ & PS vs. PK (0.042) \\
\hline & $T_{f}$ & $683(391-1,021)$ & $709(296-1,385)$ & $1,432(809-2,025)$ & $0.003^{*}$ & PS vs. PK (0.006) \\
\hline
\end{tabular}

Values are presented as median (25th-75th quartile interquartile range).

Group PS, patients to receive normal saline; group PD, patients to receive $0.5 \mu \mathrm{g} / \mathrm{kg} / \mathrm{hr}$ dexmedetomidine; group PK, patients to receive $0.5 \mathrm{mg} / \mathrm{kg} / \mathrm{hr}$ ketamine; $\mathrm{T}_{\mathrm{i}}$, time taken to achieve train of four ratio $>90 \%$ after starting the study drug infusion; $T_{30}, 30$ minutes after $T_{i} ; T_{60}, 60$ minutes after $T_{i} ; T_{f}$, at the end of spine instrumentation/ manipulation.

${ }^{*} p<0.05$ (statistically significant).

Table 3. Change (\%) in the median amplitudes from baseline in study groups

\begin{tabular}{|llccc}
\multirow{2}{*}{ Groups } & \multicolumn{3}{c}{ Muscle groups } & \multicolumn{3}{c}{ \% Change } \\
\cline { 3 - 5 } & & at $\mathrm{T}_{30}$ & at $\mathrm{T}_{60}$ & at $\mathrm{T}_{\mathrm{f}}$ \\
\hline PS & Right tibialis anterior & +2.7 & +1 & -11 \\
& Left tibialis anterior & -0.1 & -11 & -12 \\
\hline & Right abductor halluces & -0.2 & -12 & +0.9 \\
\hline PD & Left abductor halluces & -2 & -11 & -10 \\
\hline & Right tibialis anterior & +39 & +44 & +24 \\
\hline & Left tibialis anterior & +67 & +82 & +101 \\
\hline & Right abductor halluces & +11 & +25 & +18 \\
\hline PK & Left abductor halluces & +0.5 & +62 & +27 \\
\hline & Right tibialis anterior & +26 & +60 & +62 \\
& Left tibialis anterior & +36 & +53 & +90 \\
\hline & Right abductor halluces & +24 & +44 & +79 \\
\hline & Left abductor halluces & +38 & +62 & +100 \\
\hline
\end{tabular}

Group PS, patients to receive normal saline; group PD, patients to receive 0.5 $\mu \mathrm{g} / \mathrm{kg} / \mathrm{hr}$ dexmedetomidine; group PK, patients to receive $0.5 \mathrm{mg} / \mathrm{kg} / \mathrm{hr}$ ketamine; $T_{i}$, time taken to achieve train of four ratio $>90 \%$ after starting the study drug infusion; $T_{30}, 30$ minutes after $T_{i} ; T_{60}, 60$ minutes after $T_{i} ; T_{f}$, at the end of spine instrumentation/manipulation.
Table 4. Latency at different time interval in study groups

\begin{tabular}{|c|c|c|c|c|c|}
\hline Latency (msec) & Time & Group PS & Group PD & Group PK & $p$-value \\
\hline \multirow[t]{4}{*}{ Right tibialis anterior } & $T_{i}$ & $29.29 \pm 2.61$ & $30.77 \pm 3.15$ & $29.33 \pm 2.66$ & 0.073 \\
\hline & $\mathrm{T}_{30}$ & $29.41 \pm 2.34$ & $31.11 \pm 2.96$ & $29.88 \pm 3.07$ & 0.060 \\
\hline & $\mathrm{T}_{60}$ & $30.57 \pm 2.27$ & $31.06 \pm 2.36$ & $29.47 \pm 3.12$ & 0.061 \\
\hline & $T_{f}$ & $30.41 \pm 2.91$ & $30.86 \pm 2.86$ & $30.59 \pm 2.92$ & 0.826 \\
\hline \multirow[t]{4}{*}{ Left tibialis anterior } & $T_{i}$ & $29.81 \pm 2.59$ & $31.48 \pm 2.87$ & $30.53 \pm 2.49$ & 0.056 \\
\hline & $\mathrm{T}_{30}$ & $30.05 \pm 2.59$ & $31.48 \pm 2.87$ & $30.53 \pm 2.49$ & 0.076 \\
\hline & $\mathrm{T}_{60}$ & $31.25 \pm 2.44$ & $31.80 \pm 2.17$ & $31.33 \pm 3.04$ & 0.653 \\
\hline & $T_{f}$ & $30.59 \pm 2.89$ & $31.86 \pm 2.39$ & $31.03 \pm 2.61$ & 0.177 \\
\hline \multirow[t]{4}{*}{ Right abductor halluces } & $T_{i}$ & $46.13 \pm 3.68$ & $49.09 \pm 5.89$ & $47.99 \pm 4.98$ & 0.069 \\
\hline & $\mathrm{T}_{30}$ & $46.88 \pm 3.74$ & $49.40 \pm 6.03$ & $49.07 \pm 4.38$ & 0.135 \\
\hline & $\mathrm{T}_{60}$ & $46.59 \pm 3.66$ & $49.02 \pm 5.86$ & $47.38 \pm 4.74$ & 0.148 \\
\hline & $T_{f}$ & $61.97 \pm 4.3$ & $48.52 \pm 5.20$ & $47.84 \pm 4.89$ & 0.470 \\
\hline \multirow[t]{4}{*}{ Left abductor halluces } & $T_{i}$ & $46.18 \pm 3.79$ & $49.17 \pm 5.80$ & $48.79 \pm 5.58$ & 0.054 \\
\hline & $\mathrm{T}_{30}$ & $46.36 \pm 4.23$ & $48.89 \pm 5.09$ & $48.77 \pm 5.45$ & 0.088 \\
\hline & $T_{60}$ & $47.10 \pm 4.04$ & $48.84 \pm 4.96$ & $48.66 \pm 4.48$ & 0.265 \\
\hline & $T_{f}$ & $47.67 \pm 4.03$ & $49.05 \pm 4.55$ & $48.84 \pm 4.96$ & 0.449 \\
\hline
\end{tabular}

Values are presented as mean \pm standard deviation

Group PS, patients to receive normal saline; group PD, patients to receive 0.5 $\mu \mathrm{g} / \mathrm{kg} / \mathrm{hr}$ dexmedetomidine; group PK, patients to receive $0.5 \mathrm{mg} / \mathrm{kg} / \mathrm{hr}$ ketamine; $T_{i}$, time taken to achieve train of four ratio $>90 \%$ after starting the study drug infusion; $T_{30}, 30$ minutes after $T_{i} ; T_{60}, 60$ minutes after $T_{i} ; T_{f}$, at the end of spine instrumentation/manipulation. 

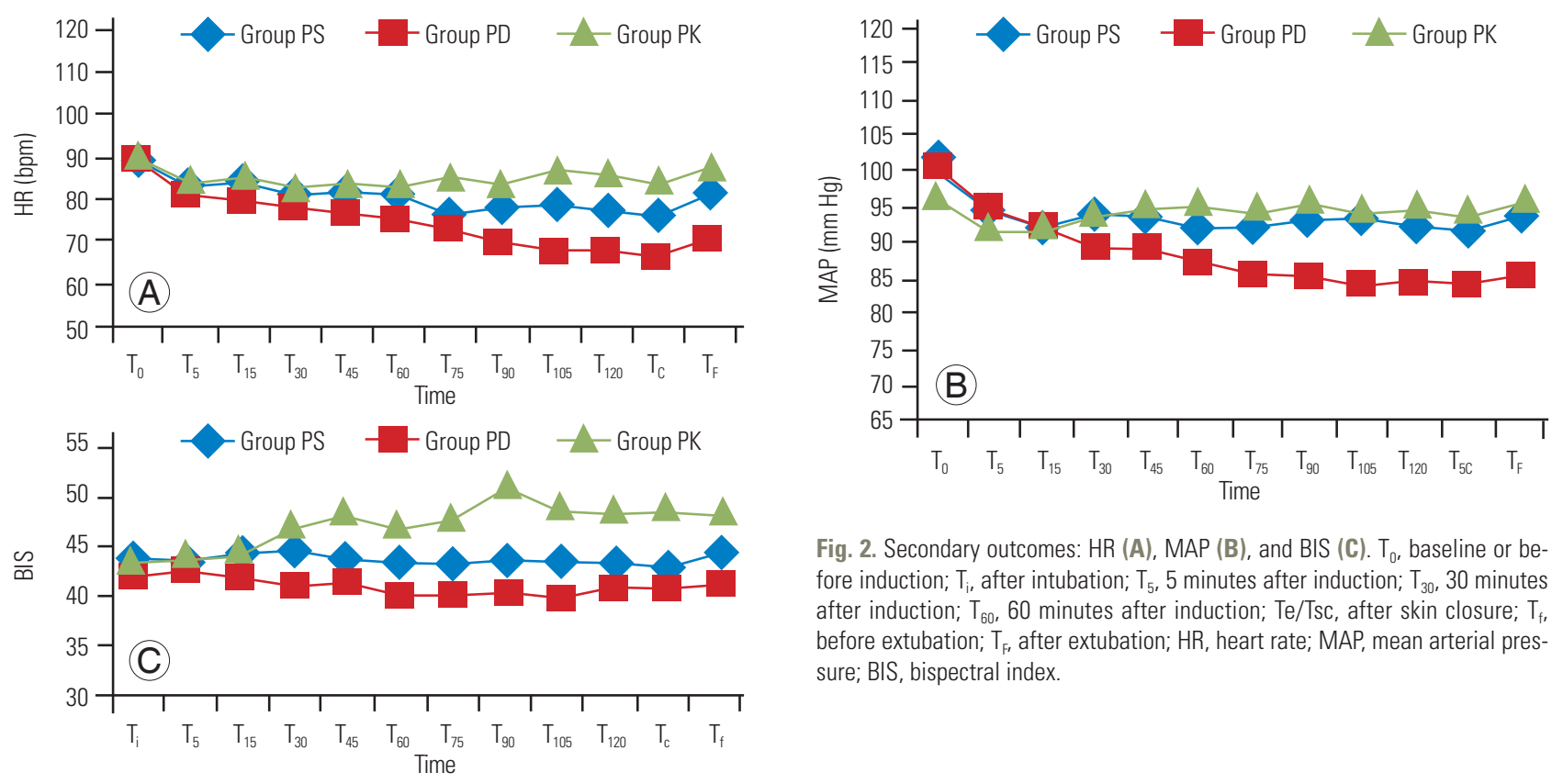

Fig. 2. Secondary outcomes: HR (A), MAP (B), and BIS (C). $T_{0}$, baseline or before induction; $T_{i}$, after intubation; $T_{5}, 5$ minutes after induction; $T_{30}, 30$ minutes after induction; $T_{60}, 60$ minutes after induction; Te/Tsc, after skin closure; $T_{f}$, before extubation; $T_{F}$, after extubation; $H R$, heart rate; MAP, mean arterial pressure; BIS, bispectral index.

Table 5. Secondary outcomes

\begin{tabular}{|c|c|c|c|c|c|}
\hline Variable & Group PS ( $n=30$ ) & Group PD ( $n=30)$ & Group PK $(n=30)$ & $p$-value & Significant post hoc analysis \\
\hline \multicolumn{6}{|l|}{ Intraoperative drugs usage } \\
\hline Propofol (mg) & $2,174.67 \pm 400.9$ & $1,799.33 \pm 622.5$ & $2,021.67 \pm 692$ & 0.049 & PS vs. PD \\
\hline Fentanyl ( $\mu \mathrm{g})$ & $485.67 \pm 113.2$ & $455.50 \pm 155.29$ & $466.33 \pm 125.46$ & 0.674 & \\
\hline Study drugs & $31.00 \pm 9.21 \mathrm{~mL}$ & $146.50 \pm 68.85 \mu \mathrm{g}$ & $136 \pm 59.62 \mathrm{mg}$ & - & \\
\hline \multicolumn{6}{|l|}{ Recovery profiles (min) } \\
\hline Time (eye opening on command) & $18.30 \pm 6.76$ & $14.67 \pm 4.66$ & $19.63 \pm 7.66$ & 0.011 & PD vs. PK, PS vs. PD \\
\hline Time (extubation) & $18.57 \pm 6.70$ & $14.00 \pm 4.52$ & $17.73 \pm 8.06$ & 0.020 & PS vs. PD \\
\hline Complications & & & & 0.045 & \\
\hline Shivering & 1 & 0 & 1 & 0.599 & \\
\hline Delayed extubation & 2 & 0 & 1 & 0.355 & \\
\hline Facial blisters & 1 & 1 & 1 & 0.999 & \\
\hline Delirium/disorientation & 0 & 0 & 6 & 0.006 & \\
\hline Tongue bite & 0 & 0 & 1 & 0.364 & \\
\hline \multicolumn{6}{|l|}{ Postoperative pain score } \\
\hline NRS arrival in PACU & $2.3(2-4)$ & $0(0-2)$ & $1.5(0-2)$ & 0.00 & PS vs. PD, PK vs. PS \\
\hline NRS on discharge from PACU & $5(2.75-5)$ & $2(2-3)$ & $3.5(2.75-5)$ & 0.00 & PS vs. PD, PK vs. PD \\
\hline NRS at $24 \mathrm{hr}$ & $7(5.75-8)$ & $6(4-7)$ & $7(6-7)$ & 0.06 & \\
\hline Incidence of rescue analgesic requirement (yes/no) & $23 / 7$ & $16 / 14$ & $27 / 3$ & 0.05 & PD vs. PK \\
\hline
\end{tabular}

Values are presented as mean \pm standard deviation, number, or median (25th-75th interquartile range).

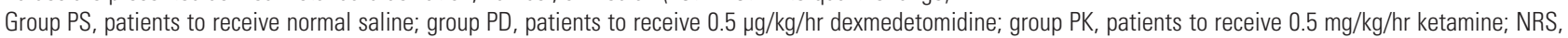
Numerical Rating Scale; PACU, post-anesthesia care unit.

MEP with $0.3-0.6 \mathrm{ng} / \mathrm{mL}$ target plasma concentration of dexmedetomidine. Mahmoud et al. [20] studied the effect of dexmedetomidine on TceMEP at 0.4, 0.6, and 0.8 $\mathrm{ng} / \mathrm{mL}$ target plasma concentration; they observed a 54\% decrease in the amplitude of the first dorsal interosseous muscle at $0.8 \mathrm{ng} / \mathrm{mL}$ compared with a $3 \%$ increase at 0.4 
$\mathrm{ng} / \mathrm{mL}$; for the tibialis anterior muscle, they observed a $57 \%$ decrease at $0.8 \mathrm{ng} / \mathrm{mL}$ and a $3 \%$ increase at $0.4 \mathrm{ng} /$ $\mathrm{mL}$. Chen et al. [21] observed recordable MEPs at a lower dose of dexmedetomidine $(0.3 \mu \mathrm{g} / \mathrm{kg}$ loading dose followed by $0.3 \mu \mathrm{g} / \mathrm{kg} / \mathrm{hr}$ ); however, the loss of waveform was observed at a higher dose $(0.8 \mu \mathrm{g} / \mathrm{kg}$ loading dose followed by $0.8 \mu \mathrm{g} / \mathrm{kg} / \mathrm{hr}$ ). Rozet et al. [22] found consistent and reliable recording of MEPs with $0.6 \mu \mathrm{g} / \mathrm{kg} / \mathrm{hr}$ dexmedetomidine. Li et al. [23] evaluated the effect of the addition of dexmedetomidine $(0.5 \mu \mathrm{g} / \mathrm{kg}$ over 10 minutes followed by $0.5 \mu \mathrm{g} / \mathrm{kg} / \mathrm{hr}$ ) to the propofol-remifentanil target-controlled infusion regime on MEPs and found no significant changes in the amplitude and latency on intergroup and intragroup analysis. We observed sporadic increments in the amplitude with dexmedetomidine throughout monitoring.

To our knowledge, only a retrospective study by Lam et al has compared the effects of ketamine and dexmedetomidine on MEPs during TIVA; no significant difference in amplitudes were observed with ketamine $(0.5 \mathrm{mg} / \mathrm{kg}$ followed by $0.2-0.5 \mathrm{mg} / \mathrm{kg} / \mathrm{hr}$ ) and dexmedetomidine (0.1-0.4 $\mu \mathrm{g} / \mathrm{kg} / \mathrm{hr}$ without a loading dose) [24].

In our study, we used higher, fixed dosages of dexmedetomidine and ketamine in infusion; this could be the reason for the significant difference in amplitudes between the study groups. We also avoided nitrous oxide for the maintenance of anesthesia; this might be responsible for the MEP response-enhancing effect of ketamine in our study. Propofol infusion is stated as a reason for the dosedependent decrease in amplitude by several researchers $[2,4]$. We also observed a similar trend in our control group, with $0.1 \%-12 \%$ depression in MEP responses with $50-150 \mu \mathrm{g} / \mathrm{kg} / \mathrm{min}$ propofol.

The drugs used in our study did not significantly affect the latency. The nonsignificant effects of dexmedetomidine, ketamine, or anesthetic agents on the latency of MEP have been recorded in the literature [8-15].

Combining dexmedetomidine with propofol infusion in TIVA is advantageous. The proposed advantages are reduced intraoperative consumption of propofol and opioids, intraoperative hemodynamic stability, and postoperative pain relief. We observed lower intraoperative consumption of propofol with dexmedetomidine; various studies have reported reduced propofol usage with $0.3-0.8$ $\mu \mathrm{g} / \mathrm{kg} / \mathrm{hr}$ dexmedetomidine infusion [20-23]. Tsaousi et al. [25] concluded that dexmedetomidine at relatively low dose $(0.2-0.5 \mu \mathrm{g} / \mathrm{kg} / \mathrm{hr})$ significantly reduces the total in- traoperative consumption of propofol (mean difference, $-214.47 \mathrm{mg}$; $95 \%$ confidence interval, -253.16 to -175.78 ; $p<0.001)$ during spine surgery. We could not observe the opioid-sparing effects of dexmedetomidine because fentanyl infusion was a part of the TIVA regime.

Loftus et al. [26] and Maheshwari et al. [27] have demonstrated comparable results of intraoperative fentanyl and propofol usage with intraoperative ketamine infusion at 0.6 and $0.3 \mathrm{mg} / \mathrm{kg} / \mathrm{hr}$, respectively.

The total duration of postoperative analgesia as assessed using the NRS score was higher in the dexmedetomidine group than in the ketamine group.

The use of dexmedetomidine or ketamine was associated with contradictory effects on hemodynamic variables. Heart rate and MAP were lower in the dexmedetomidine group, whereas they were higher in the ketamine group. This difference in heart rate and MAP became significant after 60 minutes and 75 minutes of starting the drug infusion, respectively. Dexmedetomidine decreased the MAP and heart rate by reducing norepinephrine release, and ketamine caused tachycardia and hypertension because of catecholamine release $[28,29]$. We did not administer the loading dose of the study drugs; thus, it took some time to achieve a clinical effect.

The BIS was higher with the use of ketamine infusion than with dexmedetomidine; this difference became significant within 30 minutes of starting the infusion. This increase in BIS may reflect the desynchronization of the electroencephalography signal resulting from the dissociative action of ketamine rather than from the decrease in anesthetic depth [30]. Dexmedetomidine decreases the BIS because of its sedative and hypnotic action [29].

The use of ketamine was associated with a significantly higher prevalence of complications. Dysphoria or disorientation was observed only with ketamine use. In our study, only one incidence of tongue bite was recorded in the ketamine group. This incident occurred owing to the displacement of the bite block during positioning.

Our study has certain limitations. First, our sample size was relatively small. Second, we could not measure the plasma concentration of dexmedetomidine and ketamine; thus, a fixed-dose regime may be associated with a variable plasma level. Third, the use of the analgesia nociception index would have demonstrated a better intraoperative requirement of opioids and would have inferred the opioid-sparing effect of the study drugs more precisely. Further studies on a larger sample are warranted to confirm our findings. 


\section{Conclusions}

In conclusion, in this study, compared with dexmedetomidine, a subanesthetic dose of ketamine achieved gradual improvement in amplitudes without affecting the latency of the MEPs. However, this effect was not associated with a reduction in the perioperative dosage of propofol.

\section{Conflict of Interest}

No potential conflict of interest relevant to this article was reported.

\section{Author Contribution}

Roshan Andleeb: data collection, analysis of data, drafting and review of manuscript; Sanjay Agrawal: study design, data collection, drafting and critical review of manuscript; and Priyanka Gupta: study design, critical review of manuscript.

\section{References}

1. Thirumala PD, Crammond DJ, Loke YK, Cheng HL, Huang J, Balzer JR. Diagnostic accuracy of motor evoked potentials to detect neurological deficit during idiopathic scoliosis correction: a systematic review. J Neurosurg Spine 2017;26:374-83.

2. Wang AC, Than KD, Etame AB, La Marca F, Park P. Impact of anesthesia on transcranial electric motor evoked potential monitoring during spine surgery: a review of the literature. Neurosurg Focus 2009;27:E7.

3. Macdonald DB, Skinner S, Shils J, Yingling C; American Society of Neurophysiological Monitoring. Intraoperative motor evoked potential monitoring: a position statement by the American Society of Neurophysiological Monitoring. Clin Neurophysiol 2013;124:2291-316.

4. Nathan N, Tabaraud F, Lacroix F, et al. Influence of propofol concentrations on multipulse transcranial motor evoked potentials. Br J Anaesth 2003;91:493-7.

5. Pascoe PJ, Ilkiw JE, Frischmeyer KJ. The effect of the duration of propofol administration on recovery from anesthesia in cats. Vet Anaesth Analg 2006;33:2-7.

6. Ushirozako H, Yoshida G, Kobayashi S, et al. Impact of total propofol dose during spinal surgery: anes- thetic fade on transcranial motor evoked potentials. J Neurosurg Spine 2019:1-9.

7. Walker CT, Kim HJ, Park P, et al. Neuroanesthesia guidelines for optimizing transcranial motor evoked potential neuromonitoring during deformity and complex spinal surgery: a Delphi consensus study. Spine (Phila Pa 1976) 2020;45:911-20.

8. Kalkman CJ, Drummond JC, Patel PM, Sano T, Chesnut RM. Effects of droperidol, pentobarbital, and ketamine on myogenic transcranial magnetic motor-evoked responses in humans. Neurosurgery 1994;35:1066-71.

9. Kothbauer K, Schmid UD, Liechti S, Rosler KM. The effect of ketamine anesthetic induction on muscle responses to transcranial magnetic cortex stimulation studied in man. Neurosci Lett 1993;154:105-8.

10. Inoue S, Kawaguchi M, Kakimoto M, et al. Amplitudes and intrapatient variability of myogenic motor evoked potentials to transcranial electrical stimulation during ketamine/N2O- and propofol/N2O-based anesthesia. J Neurosurg Anesthesiol 2002;14:213-7.

11. Ubags LH, Kalkman CJ, Been HD, Porsius M, Drummond JC. The use of ketamine or etomidate to supplement sufentanil/N2O anesthesia does not disrupt monitoring of myogenic transcranial motor evoked responses. J Neurosurg Anesthesiol 1997;9:228-33.

12. Benuska J, Plisova M, Zabka M, Horvath J, Tisovsky P, Novorolsky K. The influence of anesthesia on intraoperative neurophysiological monitoring during spinal surgeries. Bratisl Lek Listy 2019;120:794-801.

13. Sihle-Wissel M, Scholz M, Cunitz G. Transcranial magnetic-evoked potentials under total intravenous anaesthesia and nitrous oxide. Br J Anaesth 2000;85:465-7.

14. Yang LH, Lin SM, Lee WY, Liu CC. Intraoperative transcranial electrical motor evoked potential monitoring during spinal surgery under intravenous ketamine or etomidate anaesthesia. Acta Neurochir (Wien) 1994;127:191-8.

15. Anschel DJ, Aherne A, Soto RG, et al. Successful intraoperative spinal cord monitoring during scoliosis surgery using a total intravenous anesthetic regimen including dexmedetomidine. J Clin Neurophysiol 2008;25:56-61.

16. Sim J, Lewis M. The size of a pilot study for a clinical trial should be calculated in relation to considerations of precision and efficiency. J Clin Epidemiol 
2012;65:301-8

17. Di Lazzaro V, Oliviero A, Profice P, et al. Ketamine increases human motor cortex excitability to transcranial magnetic stimulation. J Physiol 2003;547(Pt 2):485-96

18. Tobias JD, Goble TJ, Bates G, Anderson JT, Hoernschemeyer DG. Effects of dexmedetomidine on intraoperative motor and somatosensory evoked potential monitoring during spinal surgery in adolescents. Paediatr Anaesth 2008;18:1082-8.

19. Bala E, Sessler DI, Nair DR, McLain R, Dalton JE, Farag E. Motor and somatosensory evoked potentials are well maintained in patients given dexmedetomidine during spine surgery. Anesthesiology 2008;109:417-25.

20. Mahmoud M, Sadhasivam S, Salisbury S, et al. Susceptibility of transcranial electric motor-evoked potentials to varying targeted blood levels of dexmedetomidine during spine surgery. Anesthesiology 2010;112:1364-73.

21. Chen Z, Lin S, Shao W. Effects on somatosensory and motor evoked potentials of senile patients using different doses of dexmedetomidine during spine surgery. Ir J Med Sci 2015;184:813-8.

22. Rozet I, Metzner J, Brown M, et al. Dexmedetomidine does not affect evoked potentials during spine surgery. Anesth Analg 2015;121:492-501.

23. Li Y, Meng L, Peng Y, et al. Effects of dexmedetomidine on motor- and somatosensory-evoked potentials in patients with thoracic spinal cord tumor: a randomized controlled trial. BMC Anesthesiol 2016;16:51.
24. Lam S, Nagata M, Sandhu SK, Veselis RA, McCormick PJ. Effect of ketamine on transcranial motorevoked potentials during spinal surgery: a pilot study. Br J Anaesth 2019;123:e530-2.

25. Tsaousi GG, Pourzitaki C, Aloisio S, Bilotta F. Dexmedetomidine as a sedative and analgesic adjuvant in spine surgery: a systematic review and meta-analysis of randomized controlled trials. Eur J Clin Pharmacol 2018;74:1377-89.

26. Loftus RW, Yeager MP, Clark JA, et al. Intraoperative ketamine reduces perioperative opiate consumption in opiate-dependent patients with chronic back pain undergoing back surgery. Anesthesiology 2010;113:639-46.

27. Maheshwari K, Avitsian R, Sessler DI, et al. Multimodal analgesic regimen for spine surgery: a randomized placebo-controlled trial. Anesthesiology 2020;132:992-1002.

28. Pekoe GM, Smith DJ. The involvement of opiate and monoaminergic neuronal systems in the analgesic effects of ketamine. Pain 1982;12:57-73.

29. Hall JE, Uhrich TD, Barney JA, Arain SR, Ebert TJ. Sedative, amnestic, and analgesic properties of smalldose dexmedetomidine infusions. Anesth Analg 2000;90:699-705.

30. Schuler SS, Petersen CL, West NC, Ansermino JM, Merchant RN, Gorges M. The effect of ketamine on depth of hypnosis indices during total intravenous anesthesia-a comparative study using a novel electroencephalography case replay system. J Clin Monit Comput 2020 Jul 25 [Epub]. https://doi.org/10.1007/s10877-020-00565-0. 